Cahiers $d u$ MONDE RUSSE

\section{Cahiers du monde russe}

Russie - Empire russe - Union soviétique et États indépendants

$49 / 4 \mid 2008$

Destins individuels et terreur. Jeunesse dans la société post-stalinienne

\title{
Gail Buyske, Banking on Small Business
}

\section{Caroline Dufy}

\section{(2) OpenEdition}

1 Journals

\section{Édition électronique}

URL : https://journals.openedition.org/monderusse/6978

DOI : 10.4000/monderusse. 6978

ISSN : $1777-5388$

Éditeur

Éditions de l'EHESS

\section{Édition imprimée}

Date de publication : 28 décembre 2008

Pagination : 797-800

ISBN : 978-2-7132-2197-2

ISSN : $1252-6576$

Référence électronique

Caroline Dufy, «Gail Buyske, Banking on Small Business », Cahiers du monde russe [En ligne], 49/4 I 2008, mis en ligne le 24 décembre 2009, consulté le 02 septembre 2022. URL : http://

journals.openedition.org/monderusse/6978; DOI : https://doi.org/10.4000/monderusse.6978

Ce document a été généré automatiquement le 2 septembre 2022

Tous droits réservés 


\title{
Gail Buyske, Banking on Small Business
}

\author{
Caroline Dufy
}

\section{RÉFÉRENCE}

Gail BUYSKE, Banking on Small Business. Microfinance in Contemporary Russia.

Ithaca-Londres : Cornell University Press, 2007, XV + 220 p.

1 Banking on Small Business. Microfinance in Contemporary Russia est l'œuvre d'une praticienne du système bancaire russe postsoviétique. Membre pendant six ans du comité de direction de la première banque du microcrédit en Russie, la banque KMB, financée avec le soutien des organisations internationales et tout particulièrement de la Banque européenne de reconstruction et de développement (BERD), l'auteur a en outre mené des missions d'expertise pour la Banque mondiale.

2 Consacrée à l'avènement du microcrédit en Russie, l'analyse couvre la période qui s'étend de la perestroïka jusqu'à 2006. L'ambition de l'ouvrage est de mettre en perspective historique la constitution du tissu des petites et moyennes entreprises russes dans un contexte où le secteur bancaire a des opportunités de profit bien plus importantes que le crédit aux PME. À travers les quatre chapitres que comporte cet ouvrage, l'auteur éclaire les différentes étapes de ce développement contradictoire, au moment où la transition à l'économie de marché libère les initiatives et prône le développement de la petite entreprise.

3 Le problème de la spécificité russe est posé d'emblée dans le premier chapitre : dans les pays émergents d'Asie et d'Amérique latine, la microfinance est une méthode nouvelle destinée à procurer des services financiers aux populations pauvres. La situation russe justifie l'adoption d'une définition plus large: le microcrédit y est destiné prioritairement aux emprunteurs exclus des circuits classiques de financement. Mais l'innovation financière que constitue le microcrédit repose également sur une méthodologie spécifique de calcul du risque où la prise en compte de la trésorerie de 
l'entrepreneur et de la relation du crédit avec le prêteur sont centrales. Le propos de l'auteur n'est d'ailleurs pas de prôner un « développementalisme " militant à vocation sociale, mais de convaincre le lecteur et les banquiers russes que le microcrédit peut être économiquement rentable.

Le second chapitre conteste une thèse répandue, celle de la faiblesse du tissu des petites entreprises dans la Russie postsoviétique. Pour l'auteur, le tissu des PME a montré une remarquable résistance compte tenu de la forte incertitude, de la grande instabilité et des crises à répétition qu'a connues la Russie dans les années 1990. Les entrepreneurs russes ont fait preuve de dynamisme et d'esprit d'initiative, alors même qu'ils étaient privés du soutien du secteur bancaire, intermédiaire principal de financement des petites entreprises dans les pays développés. Les récits de vie restitués par l'auteur témoignent de la débrouillardise manifestée par les petits entrepreneurs pour survivre au-delà des crises, mais aussi pour profiter des opportunités économiques. C'est le cas d'Oleg, un jeune provincial venu à Moscou pour monter une petite agence de publicité. La crise lui révèle la nécessité stratégique, pour développer sa société qui compte plus de 80 employés en 2005, d'intéresser ses salariés. La création de l'atelier de confection de Tatiana et de sa soeur s'enracine dans l'expérience des coopératives créées par la perestroïka. À la fin des années 1980, les deux sœurs délaissent un poste dans une grande entreprise d'État pour se lancer dans l'aventure de la mode. Les crises de 1994 et de 1998 les contraignent à un retour humiliant à la vente sur les marchés de plein air. Toutefois, la dévaluation qui résulte du krach de 1998 renchérit vêtements et textiles importés et incite les deux sœurs à trouver des partenaires financiers pour créer leur propre usine de production en Russie. Depuis lors, leur réseau de commercialisation compte cinq magasins à Moscou.

Le chapitre III, particulièrement documenté, pointe les raisons du désintérêt du secteur bancaire pour le crédit classique. Dès les années 1990, les marchés financiers et les transactions internationales apparaissent plus attractifs grâce aux bons d'État russes très rémunérateurs, mais aussi aux opérations sur les devises. Une autre spécificité du secteur bancaire russe des années 1990 est son étroite proximité avec le pouvoir, mise en exergue par l'auteur. Le président El'cin s'appuie sur les empires financiers de quelques oligarques, en particulier Boris Berezovskij et Vladimir Gusinskij, pour assurer sa réélection en 1996 et obtient de leur part un soutien à la politique de titrisation de la dette de l'État russe. Ce modèle de collusion entre l'État et les élites financières russes est remis en cause par la crise financière qui affaiblit les grandes banques russes et cause la faillite de fleurons du secteur, tels que Onexim Bank, SBS Agro et Inkombank. En 1998, le bilan dressé par l'auteur est sévère : le secteur bancaire russe a non seulement failli dans sa mission de financement de l'économie réelle, mais il a également miné la confiance d'une société en train de s'adapter à la disparition de l'économie planifiée. La crise financière marque une rupture radicale dans l'histoire du secteur bancaire postsoviétique: l'activité de crédit devient un marché à conquérir. Le contexte macroéconomique contribue également à cette réorientation, par l'intermédiaire de la diminution de l'inflation et de la baisse des taux d'emprunt, également encouragée par la hausse de la concurrence et le renforcement de la présence des banques étrangères. Le volume de crédits s'accroît, les produits se diversifient et les échéances des prêts s'allongent.

6 L'histoire de la banque KMB est restituée dans le quatrième chapitre. Les éléments produits sont précis: les comptes rendus d'activité donnés sur la période 2000-2005 
mettent en évidence la croissance de l'activité de la banque, en même temps que la hausse du montant moyen des crédits accordés. Toutefois ces éléments ne peuvent qu'illustrer une tendance générale, sans la fonder. L'auteur concède d'ailleurs que l'apport de la banque KMB au financement des entreprises russes est limité : s'il constitue la quasi-totalité du microcrédit attribué dans les années 2000, il ne représente pourtant que $1 \%$ du volume total des prêts accordés.

7 L'ouvrage de Gail Buyske propose donc une contribution très appréciable à la connaissance du système bancaire postsoviétique. Il fournit des informations précieuses compte tenu de la littérature existante, majoritairement composée de rapports d'activité de la Banque centrale de Russie ou de travaux normatifs menés par les départements de recherche des banques occidentales ou des organisations internationales. Ici, la perspective est institutionnelle et politique: elle restitue finement les relations des acteurs économiques avec les pouvoirs publics, qu'ils soient fédéraux ou locaux et analyse avec précision les contradictions entre les différents niveaux de pouvoir dans la mise en place des politiques publiques. Dans cette perspective, l'analyse consacrée à la difficile conquête de sa légitimité par la Banque centrale russe est particulièrement intéressante. Implicitement, l'auteur valide les thèses institutionnalistes qui font du changement économique un processus de longue haleine, s'appuyant nécessairement sur des héritages du passé et en contradiction avec les desseins téléologiques des réformateurs radicaux. En l'occurrence, le passage de la monobanque soviétique, où les crédits sont accordés par le plan, à un système bancaire hiérarchisé à deux niveaux est effectué au début de la décennie 1990. Toutefois, le contrôle du superviseur sur les banques de second rang ne s'impose qu'au gré des crises et ne devient réellement contraignant qu'à la fin de la décennie 2000 .

8 Les matériaux utilisés par l'auteur sont vivants et diversifiés: des entretiens menés auprès de chefs d'entreprises, de banquiers ou de responsables d'associations d'entrepreneurs actualisent et éclairent les statistiques et données collectées dans la presse. La période évoquée est vécue par l'auteur, comme l'attestent les références nombreuses à des conférences, forums ou congrès auxquels il a assisté. Un index détaillé à la fin de l'ouvrage constitue un outil fort utile au lecteur pour évoluer à travers les divers chapitres.

9 La microfinance constitue en effet l'axe central du livre, son point de départ et son aboutissement. Or, et c'est l'un des principaux questionnements que l'on peut formuler à l'égard de la démarche de l'auteur, on peut raisonnablement s'interroger sur la place réelle de la microfinance dans l'économie russe. Le microcrédit n'apparaît que comme l'un des moyens susceptibles de résoudre les problèmes de financement des PME. Comme l'expose Gail Buyske, la réorientation de l'activité des grandes banques vers le crédit se fait après 2000. Les banques régionales, dont les rapports officiels déplorent le trop grand nombre, contribuent toutefois à satisfaire les besoins locaux de financement sur toute la période. Or elles demeurent très mal connues et peu étudiées. Par ailleurs, si dans les années 1990 le crédit n'est accordé que de façon résiduelle par le secteur bancaire, il fonctionne toutefois dans l'informalité, en particulier par le biais de prêts familiaux, par le recours à des formes de tontine ou à des usuriers. Mais cette dimension reste également dans l'ombre. Le lecteur pourra enfin regretter l'absence de données sur les professions bancaires et les employés ou cadres des structures bancaires, compte tenu de l'inexistence de cette profession dans la période soviétique. Les oligarques émergent comme figure centrale de la grande banque des années 1990. Toutefois, après le krach de 
1998, l'activité bancaire apparaît beaucoup moins rentable et on sait peu de chose sur les petits banquiers régionaux, mais aussi sur les employés et cadres du secteur bancaire. L'une des hypothèses que l'on peut formuler pour rendre compte de la réorientation du secteur bancaire vers le crédit est celle de l'apparition et de l'institutionnalisation de la profession de banquier.

10 La conclusion de l'ouvrage porte à penser que le système bancaire russe est parvenu à une phase de maturité et de consolidation. Toutefois la crise financière de 2007-2008 qui touche les banques russes de plein fouet invite à penser que l'histoire n'est pas close et que la vie du système bancaire russe est tout sauf un long fleuve tranquille. 